\title{
Oxidative Stress after Iron Supplementation in Crohn's Disease
}

Marcia Morandi Varela Junqueira-Franco, Carolina Ferreira Nicoletti, Carla Barbosa Nonino, Hélio Vannucchi and Julio Sergio Marchini* Internal Medicine Department, University of São Paulo, Brazil

*Corresponding author: Julio Sergio Marchini, Internal Medicine Department, University of São Paulo, Brazil, Tel: +551633153375; E-mail: jsmarchi@fmrp.usp.br Rec date: Jan 21, 2016; Acc date: Sep 22, 2016; Pub date: Sep 27, 2016

Copyright: (c) 2016 Franco MMVJ, et al. This is an open-access article distributed under the terms of the Creative Commons Attribution License, which permits unrestricted use, distribution, and reproduction in any medium, provided the original author and source are credited.

\begin{abstract}
Crohn's disease is a chronic inflammatory intestinal disease associated with increased of pro-inflammatory cytokines, iron deficiency and anaemia. This case report demonstrates a strategy for intravenous iron supplementation in a patient with Crohn's disease and severe anaemia. This study found an increased in iron and haemoglobin concentrations, malondialdehyde and superoxide dismutase levels and a reduction in glutathione peroxidase (GPx), vitamin A and $\mathrm{E}$. In conclusion the use of intravenous iron probably leads to increase ROS production; this effect may be reduced by using polivitaminics, and enhanced the free radical scavenger.
\end{abstract}

Keywords: Crohn's disease; Anaemia; Iron supplementation; Iron deficiency; Oxidative stress

\section{Introduction}

Crohn's disease (CD) is an idiopathic chronic inflammatory intestinal disease (IBD) [1] that affects gastrointestinal tract [2]. This disease is characterized by mucosal white blood cells infiltration, proinflammatory cytokines and reactive oxygen species (ROS) production. In this context, oxidative stress control is important factor in the IBD progression and recovering [1]. Moreover, severe anaemia is a common complication of IBD, affecting $6 \%$ to $74 \%$ of the patients [3], having great impact on the mortality [4,5]. The etiology of anaemia in IBD is multifactorial [6], however, iron deficiency (ID) is the primary cause $[7,8]$.

\section{Case Report}

In this case report, we describe a Caucasian, 18 years-old men with Crohn's disease who is treated in an Academic Public Hospital. He was a non-smoker, non-alcoholic and denies illicit drug abuse. His family history included a father with obesity, hypertension, smoke habit and a healthy mother. His past medical history includes onset of diarrhoea for ten years, associated with abdominal pain, cramping, fever and vomiting, accompanied with loss of $5 \mathrm{~kg}$ in the last 8 months. The patient received sulfasalazine (50 mg every 8 hours). However, his last ambulatory evaluation revealed a protein calorie malnutrition, perianal fistula, anaemia and iron deficiency. The patient was admitted in metabolic unit of this hospital and it was immediately started iron supplementation after baseline biochemical analysis. His weight was $29.9 \mathrm{~kg}$, height $1.46 \mathrm{~m}$ and body mass index $14.0 \mathrm{~kg} / \mathrm{m}^{2}$. The supplementation was carried out for ten days, intravenous being offered $100 \mathrm{mg}$ iron per day in $200 \mathrm{ml}$ of saline $0.9 \%$. Concomitantly, the patient received parenteral vitamin $C$ supplementation $(60 \mathrm{mg} /$ day). During the supplementation, the patient remained hospitalized, with oral diet that offered daily $1200 \mathrm{kcal}, 40 \mathrm{~g}$ of protein, $200 \mathrm{~g}$ of carbohydrate and $25 \mathrm{~g}$ of lipid. Throughout the internment bowel habit remained 3 times a day. Blood samples were collected on alternate's day, after 12 hours of fasting, for biochemical analysis. Haemoglobin and plasma iron values increased (Figure 1). Also, there was an increased in malondialdehyde (MDA) and superoxide dismutase (SOD) levels and a reduction in glutathione peroxidase (GPx), vitamin $\mathrm{A}$ and $\mathrm{E}$ (Table 1). The weight remained the same $(29.8 \mathrm{~kg})$.

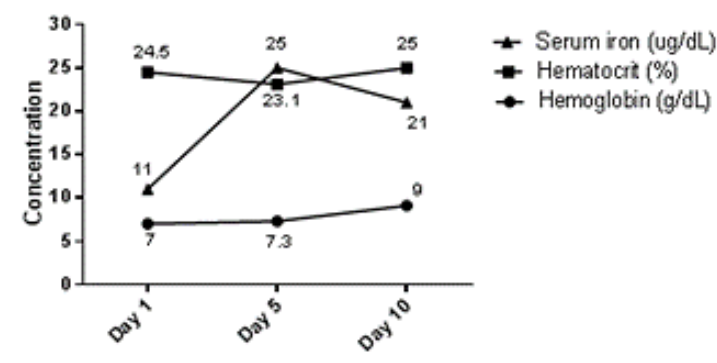

Figure 1: Serum iron, Haematocrit and haemoglobin concentration before (Day 1-Baseline) and after the iron supplementation.

\begin{tabular}{|l|l|l|l|l|l|}
\hline & $\begin{array}{l}\text { MDA } \\
(\mu \mathrm{mol} / \mathrm{l})\end{array}$ & $\begin{array}{l}\text { SOD } \\
(\mathrm{U})\end{array}$ & $\begin{array}{l}\text { GPx } \\
(\mu \mathrm{mol} / \mathrm{min} / \mathrm{Hb})\end{array}$ & $\begin{array}{l}\text { Vit A } \\
(\mu \mathrm{mol} / \mathrm{l})\end{array}$ & $\begin{array}{l}\text { Vit E } \\
(\mu \mathrm{mol} / \mathrm{l})\end{array}$ \\
\hline Day 1 (Baseline) & 1.18 & 1.05 & 20.45 & 0.16 & 4.31 \\
\hline Day 3 & 1.00 & 0.90 & 19.29 & 0.08 & 3.04 \\
\hline Day 5 & 1.02 & 1.21 & 16.97 & 0.02 & 3.81 \\
\hline
\end{tabular}


Page 2 of 3

\begin{tabular}{|l|l|l|l|l|l|}
\hline Day 7 & 4.81 & 1.44 & 17.49 & 0.08 & 2.02 \\
\hline Reference values ${ }^{*}$ & $0.18-1.02$ & $1.64-2.40$ & $>27.00$ & $0.35-1.75$ & $16.00-36.00$ \\
\hline
\end{tabular}

Table 1: Pro and anti-oxidant profile before and after iron supplementation in Crohn's patient.

\section{Discussion}

A recent meta-analysis of European studies showed an overall anaemia prevalence of $27 \%$ for CD [9]. Two recent Scandinavian studies showed a significant decrease of the prevalence of anaemia in IBD during the disease course [10,11]. Indeed, Wiskin et al. [12], showed that $30 \%$ of peadiatric IBD patients had persistent anaemia 2 years after diagnosis. In IBD cases, the intestinal blood loss and the reduced iron absorption due to inflammatory bowel, may lead to a negative iron balance [6]. However, causes of iron deficiency also could be self-imposed dietary restrictions in an attempt to improve or relieve gastrointestinal symptoms [13]. On the other hand, the inflammation results in interleukin- 6 secretion that causes an increase in hepatic hepcidin synthesis, which potentially decreases iron duodenal absorption [14]. In this context, iron supplementation should be considered in cases of ID with or without anaemia [15]. Moreover, in presence of IBD, activated T lymphocytes reduce oral iron absorption. Thus, evidences indicate that less than half of the patients receiving oral iron supplementation tolerate the dose required to normalizer iron and haemoglobin levels [16]. In addition, recent evidences showed that patients with a high degree of inflammation evidenced by elevated Creactive protein levels may take longer to respond to the oral treatment of iron [17]. In contrast, responsiveness to intra-venous treatment appears to be independent of the inflammatory status of IBD patients [18]. Thus, intravenous iron supplementation should then be employed, showing a more effective response, promoting faster improvement of haemoglobin $[8,19]$.

The only treatment option for ID is iron supplementation with metal ions. Iron frequently have unsaturated electrons, and is involved in the Fenton reaction, generating the highly reactive hydroxyl radical $(-\mathrm{OH})$. Furthermore, iron is incorporated into and is essential for the function of ROS-producing enzymes such as nicotinamide adenine dinucleotide phosphate hydride (NADPH) oxidases [20]. The chemical properties of iron render it a potential hazard within the organism in that ferrous ion $\left(\mathrm{Fe}^{2+}\right)$, in small non-protein shielded chelates, can catalyze the production of ROS, which in turn can lead to peroxidation and radical chain reactions with molecular damage [21]. There is direct and indirect evidence suggesting that the chronically inflamed intestines of Crohn's patients may be subjected to considerable oxidative stress. Although certain amounts of iron and reactive oxygen species may play an important role in CD.

Moreover, the balance of ROS concentrations is supported by antioxidant defense mechanisms include vitamins, the enzymes SOD, GPx and transient ions such as $\mathrm{Fe}^{2+}$ and $\mathrm{Cu}^{2+}$ [22]. However, Crohn's patients have low blood levels of vitamin $\mathrm{C}$ and $\mathrm{E}$ [23]. They also have low levels of $\mathrm{Cu}, \mathrm{Zn}, \mathrm{SOD}, \mathrm{GPx}$, catalase, vitamin $\mathrm{A}$ and $\beta$-carotene in their intestinal mucosa, submucosa and muscularisserosa [24]. Corroborating with this, data found in the present study showed an increased level of MDA and low levels of vitamin E, SOD and GPx at the initial of treatment and remained after iron supplementation. This coincidence of increased levels of ROS and decreased levels of antioxidant defenses results in a state of oxidative stress in Crohn's strictures [25].

In the present study, the patient did a treatment with a sulfasalazine (SAZ) that is a prodrug composed by a molecule of 5 -aminosalicylic acid (5-ASA), linked by an azo bond, which has been shown to be effective in the therapy of IBD such as ulcerative colitis and CD. The point is well known that the oral administration of SAZ is capable of reducing the mucosal injury and inflammation associated with Crohn's disease, where 5-ASA is the pharmacologically active moiety of SAZ [25]. It has been suggested that 5-ASA protects the gut mucosa by inhibiting cyclooxygenase and lipoxygenase activities [25]. Nielsen et al. [26] demonstrated a high rate of lipid peroxidation in the gut mucosa obtained from patients with IBD. They also reported a significant inhibition in lipid peroxidation among patients who had been treated with SAZ for 5 weeks [27]. In our study the use of sulfasalazine for 10 days did not change the antioxidants and MDA levels, maybe because the iron treatment had a potential proxidant effect.

In conclusion the use of intravenous iron probably leads to increase ROS production; this effect may be reduced by using polivitaminics, and enhanced the free radical scavenger. More work is needed in this area with anaemia treatment and prevention the effects of ROS in Crohn's disease.

\section{References}

1. Biasi F, Leonarduzzi G, Oteiza PI, Poli G (2013) Inflammatory bowel disease: mechanisms, redox considerations, and therapeutic targets. Antioxid Redox Signal 19: 1711-1747.

2. de Souza GS, Vidigal FM, Chebli LA, da Rocha Ribeiro TC, Furtado MC, et al. (2013) Effect of azathioprine or mesalazine therapy on incidence of re-hospitalization in sub-occlusive ileocecal Crohn's disease patients. Med Sci Monit 19: 716-722.

3. Wilson A, Reyes E, Ofman J (2004) Prevalence and outcomes of anaemia in inflammatory bowel disease: a systematic review of the literature. Am J Med 116(7A): 44S-49S.

4. Cucino C, Sonnenberg A (2001) Cause o death in patients with inflammatory bowel disease. Inflamm Bowel Dis 7: 250-255.

5. Guagnozzi D, Lucendo AJ (2014) Anaemia in inflammatory bowel disease: a neglected issue with relevant effects. World J Gastroenterol 20: 3542-3551.

6. Gomollón F, Gisbert JP (2009) Anaemia and inflammatory bowel diseases. World J Gastroenterol 15: 4659-4665.

7. 7. Kulnigg S, Gasche C (2006) Systematic review: managing anaemia in Crohn's disease. Aliment Pharmacol Ther 24: 1507-1523.

8. Dignass AU, Gasche C, Bettenworth D, Birgegård G, Danese S, et al. (2015) European consensus on the diagnosis and management of iron deficiency and anaemia in inflammatory bowel diseases. J Crohns Colitis 9: 211-222.

9. Filmann N, Rey J, Schneeweiss S, Ardizzone S, Bager P, et al. (2014) Prevalence of anaemia in inflammatory bowel diseases in european 
Citation: Junqueira-Franco MVM, Nicoletti CF, Nonino CB, Vannucchi H, Marchini JS (2016) Oxidative Stress after Iron Supplementation in Crohn's Disease. J Clin Case Rep 6: 858. doi:10.4172/2165-7920.1000858

Page 3 of 3

countries: a systematic review and individual patient data meta-analysis Inflamm Bowel Dis 20: 936-945.

10. Høivik ML, Reinisch W, Cvancarova M, Moum B; IBSEN study group (2014) Anaemia in inflammatory bowel disease: a population-based 10 year follow-up. Aliment Pharmacol Ther 39: 69-76.

11. Sjoberg D, Holmstrom T, Larsson M, Nielsen AL, Holmquist L, et al. (2014) Anaemia in a population-based IBD cohort (ICURE): still high prevalence after 1 year, especially among pediatric patients. Inflamm Bowel Dis 20: 2266-2270.

12. Wiskin AE, Fleming BJ, Wootton SA, Beattie RM (2012) Anaemia and iron deficiency in children with inflammatory bowel disease. J Crohns Colitis 6: 687-691.

13. Weiss G, Goodnough LT (2005) Anaemia of chronic disease. N Engl J Med 352: 1011-1023.

14. Nemeth E, Rivera S, Gabayan V, Keller C, Taudorf S, et al. (2004) IL-6 mediates hypoferremia of inflammation by inducing the synthesis of the iron regulatory hormone hepcidin. J Clin Invest 113: 1271-1276.

15. 15. Gasche C, Lomer MC, Cavill I, Weiss G (2004) Iron, anaemia, and inflammatory bowel diseases. Gut 53: 1190-1197.

16. 16. Lindgren S, Wikman O, Befrits R, Blom H, Eriksson A, et al. (2009) Intravenous iron sucrose is superior to oral iron sulphate for correcting anaemia and restoring iron stores in IBD patients: A randomized, controlled, evaluator-blind, multicentre study. Scand J Gastroenterol 44: 838-845.

17. 17. Iqbal T, Stein J, Sharma N, Kulnigg-Dabsch S, Vel S, et al. (2015) Clinical significance of C-reactive protein levels in predicting responsiveness to iron therapy in patients with inflammatory bowel disease and iron deficiency anaemia. Dig Dis Sci 60: 1375-1381.
18. 18. Gasche C, Waldhoer T, Feichtenschlager T, Male C, Mayer A, et al. (2001) Prediction of response to iron sucrose in inflammatory bowel disease-associated anaemia. Am J Gastroenterol 96: 2382-2387.

19. 19. Khorana AA, Francis CW, Blumberg N, Culakova E, Refaai MA, et al. (2008) Blood transfusions, thrombosis, and mortality in hospitalized patients with cancer. Arch Intern Med 168: 2377-2381.

20. 20. Altun D, Kurekci AE, Gursel O, Hacihamdioglu DO, Kurt I, et al. (2014) Malondialdehyde, antioxidant enzymes, and renal tubular functions in children with iron deficiency or iron-deficiency anaemia. Biol Trace Elem Res 161: 48-56.

21. 21. Aust AE, Eveleigh JF (1999) Mechanisms of DNA oxidation. Proc Soc Exp Biol Med 222: 246-252.

22. 22. Piechota-Polanczyk A, Fichna J (2014) Review article: the role of oxidative stress in pathogenesis and treatment of inflammatory bowel diseases. Naunyn Schmiedebergs Arch Pharmacol 387: 605-620.

23. 23. Buffinton GD, Doe WF (1995) Altered ascorbic acid status in the mucosa from inflammatory bowel disease patients. Free Radic Res 22: 131-143.

24. 24. Thomson A, Hemphill D, Jeejeebhoy KN (1998) Oxidative stress and antioxidants in intestinal disease. Dig Dis 16: 152-158.

25. 25. Alzoghaibi MA (2013) Concepts of oxidative stress and antioxidant defense in Crohn's disease. World J Gastroenterol 19: 6540-6547.

26. 26. Nielsen OH, Ahnfelt-Rønne I (1991) Involvement of oxygen-derived free radicals in the pathogenesis of chronic inflammatory bowel disease. Klin Wochenschr 69: 995-1000.

27. 27. Ahnfelt-Ronne I, Nielsen $\mathrm{OH}$, Christensen A, Langholz E, Binder V, et al. (1990) Clinical evidence supporting the radical scavenger mechanism of 5-aminosalicylic acid. Gastroenterology 98: 1162-1169. 